\title{
Racial disparities in all-cause mortality among younger commercially insured women with incident metastatic breast cancer
}

\author{
Christine Leopold ${ }^{1}$, Anita K. Wagner ${ }^{1}$, Fang Zhang ${ }^{1}$, Christine Y. Lu ${ }^{1}$, Craig Earle ${ }^{2}$, Larissa \\ Nekhlyudov ${ }^{1,3}$, Dennis-Ross Degnan ${ }^{1}$, and J. Frank Wharam ${ }^{1}$ \\ ${ }^{1}$ Department of Population Medicine / Drug Policy Research Group, Harvard Medical School and \\ Harvard Pilgrim Health Care Institute \\ ${ }^{2}$ Health Service Research, Ontario Institute for Cancer Research \\ ${ }^{3}$ Department of Medicine, Brigham \& Women's Hospital, Boston, MA
}

\begin{abstract}
PURPOSE: Racial disparities in breast cancer mortality persists and are likely related to multiple factors. Over the past decade, progress has been made in treating metastatic breast cancer, particularly in younger women. Whether disparities exist in this population is unknown.

METHODS: Using administrative claims data between 2000 and 2011 (OptumInsight, Eden Prairie, MN) of members insured through a large national US health insurer, we identified women aged 25 to 64 years diagnosed with incident metastatic breast cancer diagnosed between November 1, 2000 and December 31, 2008. We examined time from diagnosis to death, with up to 3 years of follow-up. We stratified analyses by geocoded race, and socioeconomic status, age at diagnosis, morbidity score, US region of residence, urban/non-urban, and years of diagnosis. We constructed Kaplan-Meier survival plots and analyzed all-cause mortality using multivariate Cox proportional hazard models.
\end{abstract}

RESULTS: Among 6694 women with incident metastatic breast cancer (78\% Caucasian, 4\% African American, and 18\% other), we found higher mortality rates among women residing in predominantly African American versus Caucasian neighborhoods (hazard ratio, HR: 1.84; 95\% confidence interval, CI: 1.39-2.45), women with high versus lower morbidity (HR: 1.30 [1.121.51]), and women whose incident metastatic diagnosis was during 2000-2004 versus 2005-2008 (HR: 1.60 [1.39-1.83]). Caucasian (HR: 0.61 [0.52-0.71]) but not African American women (HR not significant) experienced improved mortality in 2005-2008 versus 2000-2004.

CONCLUSIONS: Despite insured status, African American women and women with multimorbidity had poorer survival. Only Caucasian women had improved mortality over time. Modifiable risk factors for increased mortality need to be addressed in order to reduce disparities.

Corresponding author: Christine Leopold, PhD, MS; Department of Population Medicine / Drug Policy Research Group, Harvard Medical School and Harvard Pilgrim Health Care Institute, Landmark Center, 401 Park Drive Suite 401, Boston, MA 02215, phone: (617)-867-44813, fax: (617)-867-44276, christine_leopold1@hphc.org.

DISCLOSURE:

Dr. Wagner and Dr. Ross-Degnan did consultancy work for IMS Consulting Group. All other authors have no conflicts to declare. 


\section{Keywords}

metastatic breast cancer; racial; disparities; mortality; claims data

\section{INTRODUCTION}

Breast cancer is among the leading causes of death of US women with an estimated 40,450 deaths in 2016 and a 5-year survival rate of $91 \%$ after any breast cancer diagnosis [1-4]. There are 246,660 new cases of breast cancer per year. Approximately 6-10\% of patients with breast cancer have metastases at diagnosis and 30-40\% will eventually develop metastatic disease [5-8]. The overexpression of the human epidermal growth factor receptor 2 (HER2/neu), which occurs in 20-25\% of breast cancer patients, is a risk factor for metastatic breast cancer (mbc) and an indication for treatment with targeted therapies such as trastuzumab [9-12]. However, metastatic breast cancer is incurable and about $50 \%$ of patients have disease progression within one year of treatment for advanced disease [13,14].

Racial disparities in breast cancer have been widely documented. Breast cancer incidence increased from 2008 to 2012 among African American women such that rates of diagnosis for African American and Caucasian women converged for the first time in 2012 [15]. Unfortunately, the disparity in breast cancer mortality continued to widen; in 2012 breast cancer death rates were $42 \%$ higher among African American than Caucasian women [15]. Compared to Caucasian women, African American women have a higher tumor grade and stage as well as younger age-at-diagnosis [16], and a greater risk of recurrence [17,18]. These differences have been associated with biological and non-biological factors. Biological factors include plasma levels of growth factors and hormones, reproductive patterns, and primary tumor characteristics such as the presence and expression of steroid and growth factor receptors [19-21]. Non-biological differences include lack of screening, delays in diagnosis and access to treatment; treatment modalities used and available; psychological, behavioral, and cultural factors; socioeconomic status (SES), and comorbidities [22-25].

African American women are also more likely to develop late stage and metastatic breast cancer $[18,26]$ often leading to higher mortality. Aizer et al. showed that racial discrepancies in mortality persisted between 1998 and 2007 with an increasing gap between African American and Caucasian breast cancer patients [27]. However, the vast majority of studies of mortality disparities among women with metastatic breast cancer have assessed elderly Medicare patients [28,29]; little is known about disparities in mortality among younger (below age 65). Further, whether disparities persist in insured populations is not known.

We examined the effect of racial disparities in all-cause mortality among a large, populationbased cohort of younger commercially insured women with incident metastatic breast cancer. 


\section{METHODS}

\section{Data source}

This study used enrollment information and administrative claims data from the Optum ${ }^{\circledR}$ Database (OptumInsight, Eden Prairie, MN) between November 1, 2000 and December 31, 2011, data drawn from a large national health insurer with members in all 50 US states. We linked socio-demographic variables derived from the 2000 US census using census block group of residence. The data vendor linked month and year of death from the Social Security Administration's Death Master files to members in our cohort [30].

\section{Study population}

We used a validated definition by Hurvitz et al. [31] of metastatic breast cancer in health insurance claims data to identify our sample. The denominator population of patients with metastatic breast cancer was drawn from women aged 25 to 64 with at least two diagnoses of "secondary malignant neoplasm" (International Classification of Diseases, Ninth Revision codes, ICD-9, 197.xx and 198.xx) between November 1, 2000, and December 31, 2008 on separate days but fewer than 91 days apart. To ensure capture of a population with incident metastatic disease, we required that these women have at least six months of enrollment before the first diagnosis of "secondary malignant neoplasm" and defined the first occurrence of this diagnosis as the disease index date. To capture a cohort with metastatic breast cancer, we required at least two independent diagnoses of breast cancer (ICD-9 codes 174-174.9, 233.0) during the 365-day period prior to the disease index date or at least one diagnosis during the 365 days before and at least one within 90 days after the disease index date. From this group, we excluded women diagnosed with other cancer types (excluding non-melanoma skin cancer) prior to the first breast cancer diagnosis claim [31] given uncertainty regarding which of the cancer diagnoses was metastatic. Figure 1 displays the cohort selection flow and relevant sample sizes.

\section{Outcomes measures}

The outcome of interest was time (in months) from the metastatic breast cancer disease index date (i.e., incident metastatic breast cancer diagnosis) to all-cause death, with up to 3 years of follow-up after this date.

\section{Covariates and stratifying variables}

We evaluated the following predictors of all-cause death: geocoded neighborhood race composition, age-at-diagnosis, comorbidity score (ACG, version 10.0.1) [32,33], geocoded socio-economic status (SES), US region of residence, urban/non-urban residence, and time period of diagnosis. Women were classified as residing in predominantly Caucasian or African American neighborhoods on the basis of living in census block groups with greater than $66 \%$ of residents of the given race. The category "mixed" neighborhood composition included women not living in predominantly Caucasian or African American neighborhoods or those with Hispanic or Asian surnames (provided by the data vendor). We classified ageat-diagnosis into 25 to 39,40 to 49 , and 50 to 64 years. To generate proxy measures of SES, previously established [34] categorical variables of census block group poverty and 
education levels derived from 2000 US Census reports were created [35]. Women were then classified as from low SES neighborhoods if they lived in census block groups with low education (more than $25 \%$ of households with less than high school education) or low income (more that $10 \%$ of households below poverty level). Further, during the 6 months preceding the disease index date, women were classified as having low morbidity if their morbidity score (Johns Hopkins ACG® System comorbidity score; ACG, version 10.0.1) was below 3.0 and high morbidity if the ACG score was 3.0 or above. The ACG score was developed on a standardized population in which a score of 1.0 represents average health $[32,33]$. Women were also categorized by the region of the country in which they resided (Northeast, South, West, and Midwest) on the basis of their most recent zip code. Urban/ non-urban area classification was based on members' most recent zip code linked to the US Department of Agriculture commuting area codes [36]. The urban group comprised women living in large metropolitan areas of 1+ million residents and non-urban included all remaining women (urban influence codes 2-12). Finally, members were categorized as having been diagnosed earlier (2000 to 2004) or later (2005 to 2008) based on the calendar year of their disease index date.

\section{Statistical analysis}

We used multivariate Cox regression models to generate hazard ratios (HRs) and 95\% confidence intervals (CIs) to assess the independent associations of the covariates above with survival (defined as months from disease index date until death) [37]. We displayed time-to-death using Kaplan-Meier survival plots. Maximum follow-up time was 36 months and patients were censored when they turned 65 , disenrolled, died or reached end of followup, whichever date came first. Statistically significant differences in hazard ratios across categories of a predictor covariate in the Cox regression models were defined as disparities. Our primary predictor of interest was neighborhood race composition. After examining results, we also performed a post hoc analysis examining the interaction of neighborhood racial composition and time period of diagnosis to determine if mortality disparities between women from African American versus Caucasian neighborhoods increased over time. All analyses were conducted using SAS (model 9.3). The research protocol was approved by the Harvard Pilgrim Health Care institutional review board.

\section{RESULTS}

The cohort comprised 6694 women with incident metastatic breast cancer. Seventy-eight percent $(\mathrm{n}=5234$, Table 1$)$ were from predominantly Caucasian neighborhoods and $4 \%(\mathrm{n}=$ 259) were from predominantly African American neighborhoods; $56 \%(\mathrm{n}=3768)$ were age 50 to 64 at diagnosis, $31 \%$ lived in low SES neighborhoods $(n=2051)$, most had low morbidity $(76 \%, n=5096)$. Forty-one percent of women lived in the South $(n=2769), 69 \%$ resided in urban areas $(n=4510)$, and nearly half of women $(48 \%, n=3223)$ were diagnosed with metastatic breast cancer between 2000 and 2004.

\section{3-year overall survival}

Table 1 displays unadjusted mortality rates during 3-year follow-up, Table 2 summarizes adjusted hazard ratios from the multivariate Cox model of overall survival, and Figures 2, 3 
and 4 display Kaplan-Meier plots of survival by select predictor. Thirteen percent of women $(n=884)$ died within three years of their first metastatic breast cancer diagnosis. Twentythree percent and $13 \%$ of women from predominantly African American and Caucasian (reference group) neighborhoods, respectively, died during follow-up (African American vs. Caucasian adjusted hazard ratio, HR: 1.84; 95\% confidence interval, CI: 1.39-2.45). Fifteen percent of women with high morbidity and $13 \%$ of women with low morbidity (reference group) died (HR: 1.30; 95\% CI: 1.12-1.51). Nine percent of women living in the Northeast died during follow-up compared with $14 \%$ of women living in the South (reference group; HR: 0.73 ; 95\% CI: 0.56-0.95). Corresponding mortality rates among women whose cancer was diagnosed during 2000-2004 versus 2005-2008 (reference group) were 16\% and 10\% (HR: 1.60; 95\% CI: 1.39-1.83), respectively. Our post hoc analysis revealed that mortality among women from Caucasian neighborhoods significantly improved for women diagnosed between 2005 to 2008 as compared to women diagnosed between 2000 to 2004 (10\% versus 15.5\%; 2000-2004 reference group: HR: 0.61; 95\% CI: 0.52-0.71) while corresponding mortality rates among women from African American neighborhoods were $21.7 \%$ and 23.5\% (HR and CI were not significant), respectively. The interaction of neighborhood race and time period was not significant $(\mathrm{p}=0.15)$. A Kaplan-Meier plot of this post hoc analysis is displayed in Figure 4.

\section{DISCUSSION}

In this population-based cohort of nearly 6700 younger commercially insured women with incident metastatic breast cancer, residence in predominantly African American neighborhoods was strongly correlated with earlier mortality compared with residence in predominantly Caucasian neighborhoods. In addition, women diagnosed between 20002004 had substantially higher mortality than women diagnosed between 2005-2008. We found survival disparities with respect to morbidity (high morbidity women had earlier mortality than low morbidity) and geographic region (Northeast lower than South). Importantly, mortality decreased significantly for Caucasian women who were diagnosed between 2005-2008 versus 2000-2004, but not for women from predominantly African American neighborhoods.

Our results were generally similar to previous studies of elderly breast cancer patients, but also contained several important differences in a cohort of younger commercially insured patients. As in studies among older women with metastatic breast cancer [38-41], we found improvement in overall survival over the recent decade (2000-2011) among younger commercially-insured women. General consensus is that mortality has decreased due to the widespread availability of targeted therapies such as trastuzumab for women with HER2positive disease [42]. Survival disparities by race among younger women are also similar to those documented in earlier studies of older women [43-45]. Several biological factors (such as aggressive histopathology, larger tumor size at presentation, greater nodal involvement, and negative estrogen receptor status) and non-biological factors (such as access to screening and care) have been cited as reasons for differential survival. As shown by the registHER study and a study by Ooi et al., African American breast cancer patients are more likely to have ER/PR-negative and triple-negative tumors than European American and non-Hispanic white breast cancer patients [23,46], and no targeted therapies are available for these 
patients. Also similar to previous studies [47-50], we found that high morbidity was associated with higher mortality among women with metastatic breast cancer. Further, our findings regarding geographic disparities with better overall survival for women living in the Northeast as compared to living in the South mirror findings by DeSanit et al., who showed that death rates decreased faster in the Northeast as compared to the South during the timeframe 1975 to 2004 [51]. A second study DeSanit et al. detected a striking worsening in long-term mortality trends among African American compared with Caucasian women [15]. Our study of younger commercially insured women confirms this divergence: Caucasian but not African American women experienced substantial increases in survival between 20002004 and 2005-2008. It is possible that differential HER2-positive status between African American and Caucasian women, compounded by differential access to effective therapies such as trastuzumab, might explain differences in survival over time.

Unlike studies that used Medicare SEER data and detected survival disparities by income level among older women [52-54], we did not find that low SES predicted worse outcomes. Although the reasons for this different finding are unclear, it is possible that lower SES women who are younger and commercially insured have better access to screening and care than older, Medicare insured women with lower SES. Another reason could be that effective therapies such as trastuzumab may be less commonly offered to older women with preexisting heart conditions.

We acknowledge several limitations of this study. First, our findings are associational and we cannot make inferences about causes of mortality disparities among women with metastatic breast cancer. Second, we did not have access to screening patterns prior to diagnosis and pathology and laboratory results that could provide information about breast cancer subtypes and hormone receptor status. Third, we could not capture other potentially important predictors of survival such as reproductive patterns or physical health and diet. In addition, despite our large sample size, our study was not powered to analyze interactions between race and other predictors such as residence in a rural area or very low-income neighborhood. The small sample size of African American women likely limited our ability to detect a statistically significant difference in mortality between African American and Caucasian women over time. Finally, the census-based neighborhood characteristics we used could lead to some misclassification of women, but these variables have been validated [25] and also characterize neighborhood characteristics (such as access to local facilities) that are not captured by member-level variables.

In conclusion, we found disparities in survival by race, morbidity, and US region of residence in a cohort of younger commercially insured women with incident metastatic breast cancer. Further, Caucasian but not African American women had improved mortality over time. While differences in mortality may be based on biological and treatment factors, modifiable risk factors must be addressed. Policy makers, health plans and clinicians should consider approaches to provide timely treatment and support to women presenting with metastatic breast cancer, particularly targeting African American women and women living in potentially vulnerable geographical areas of the U.S. 


\section{Acknowledgments}

RESEARCH SUPPORT: This work was supported by a grant from the National Cancer Institute under Grant No. R01CA172639 (PI: Wharam). Dr. Leopold's salary was supported by the Thomas O. Pyle Research Scholarship from Harvard Medical School and Harvard Pilgrim Health Care Institute.

\section{REFERENCES}

1. Cancer facts \& figures 2016 [Internet] Atlanta: American Cancer Society; 2016 Available from: http://www.cancer.org/acs/groups/content/@ research/documents/document/acspc-047079.pdf

2. DeSantis CE, Bray F, Ferlay J, Lortet-Tieulent J, Anderson BO, Jemal A. International Variation in Female Breast Cancer Incidence and Mortality Rates. Cancer Epidemiol. Biomarkers Prev 2015;24:1495-506. [PubMed: 26359465]

3. Group EBCTC, others. Effects of chemotherapy and hormonal therapy for early breast cancer on recurrence and 15-year survival: an overview of the randomised trials. The Lancet 2005;365:16871717.

4. Siegel RL, Miller KD, Jemal ACancer statistics, 2016: Cancer Statistics, 2016. CA. Cancer J. Clin 2016;66:7-30.

5. Kohler BA, Sherman RL, Howlader N, Jemal A, Ryerson AB, Henry KA, et al. Annual Report to the Nation on the Status of Cancer, 1975-2011, Featuring Incidence of Breast Cancer Subtypes by Race/Ethnicity, Poverty, and State. JNCI J. Natl. Cancer Inst 2015;107:djv048-djv048. [PubMed: 25825511]

6. Khanfir A, Lahiani F, Bouzguenda R, Ayedi I, Daoud J, Frikha M. Prognostic factors and survival in metastatic breast cancer: A single institution experience. Rep. Pract. Oncol. Radiother 2013;18:12732. [PubMed: 24416543]

7. Kennecke H, Yerushalmi R, Woods R, Cheang MCU, Voduc D, Speers CH, et al. Metastatic Behavior of Breast Cancer Subtypes. J. Clin. Oncol 2010;28:3271-7. [PubMed: 20498394]

8. Alanko A, Heinonen E, Scheinin T, Tolppanen E-M, Vihko R. Significance of estrogen and progesterone receptors, disease-free interval, and site of first metastasis on survival of breast cancer patients. Cancer 1985;56:1696-700. [PubMed: 4027900]

9. Chia SK, Speers CH, D'yachkova Y, Kang A, Malfair-Taylor S, Barnett J, et al. The impact of new chemotherapeutic and hormone agents on survival in a population-based cohort of women with metastatic breast cancer. Cancer 2007;110:973-9. [PubMed: 17647245]

10. O'Shaughnessy J Extending survival with chemotherapy in metastatic breast cancer. The oncologist 2005;10:20-29. [PubMed: 16368868]

11. Extra J-M, Antoine EC, Vincent-Salomon A, Delozier T, Kerbrat P, Bethune-Volters A, et al. Efficacy of Trastuzumab in Routine Clinical Practice and After Progression for Metastatic Breast Cancer Patients: The Observational Hermine Study. The Oncologist 2010;15:799-809. [PubMed: 20671105]

12. Gianni L, Dafni U, Gelber RD, Azambuja E, Muehlbauer S, Goldhirsch A, et al. Treatment with trastuzumab for 1 year after adjuvant chemotherapy in patients with HER2-positive early breast cancer: a 4-year follow-up of a randomised controlled trial. Lancet Oncol 2011;12:236-244. [PubMed: 21354370]

13. Marty M, Cognetti F, Maraninchi D, Snyder R, Mauriac L, Tubiana-Hulin M, et al. Randomized phase II trial of the efficacy and safety of trastuzumab combined with docetaxel in patients with human epidermal growth factor receptor 2-positive metastatic breast cancer administered as firstline treatment: the M77001 study group. J. Clin. Oncol. Off. J. Am. Soc. Clin. Oncol 2005;23:4265-74.

14. Andersson M, Lidbrink E, Bjerre K, Wist E, Enevoldsen K, Jensen AB, et al. Phase III randomized study comparing docetaxel plus trastuzumab with vinorelbine plus trastuzumab as first-line therapy of metastatic or locally advanced human epidermal growth factor receptor 2-positive breast cancer: the HERNATA study. J. Clin. Oncol. Off. J. Am. Soc. Clin. Oncol 2011;29:264-71.

15. DeSantis CE, Fedewa SA, Goding Sauer A, Kramer JL, Smith RA, Jemal A. Breast cancer statistics, 2015: Convergence of incidence rates between black and white women: Breast Cancer Statistics, 2015. CA. Cancer J. Clin 2015;n/a-n/a. 
16. Stark A, Kapke A, Schultz D, Brown R, Linden M, Raju U. Advanced stages and poorly differentiated grade are associated with an increased risk of HER2/neu positive breast carcinoma only in White women: findings from a prospective cohort study of African-American and WhiteAmerican women. Breast Cancer Res. Treat 2008;107:405-14. [PubMed: 17431759]

17. Stead LA, Lash TL, Sobieraj JE, Chi DD, Westrup JL, Charlot M, et al. Triple-negative breast cancers are increased in black women regardless of age or body mass index. Breast Cancer Res. BCR 2009;11:R18. [PubMed: 19320967]

18. Danforth DN. Disparities in breast cancer outcomes between Caucasian and African American women: a model for describing the relationship of biological and nonbiological factors. Breast Cancer Res. BCR 2013;15:208-208. [PubMed: 23826992]

19. Newman LA. Breast cancer in African-American women. The oncologist 2005;10:1-14.

20. Li CI, Malone KE, Daling JR. DIfferences in breast cancer stage, treatment, and survival by race and ethnicity. Arch. Intern. Med 2003;163:49-56. [PubMed: 12523916]

21. Chlebowski RT, Chen Z, Anderson GL, Rohan T, Aragaki A, Lane D, et al. Ethnicity and breast cancer: factors influencing differences in incidence and outcome. J. Natl. Cancer Inst 2005;97:439-48. [PubMed: 15770008]

22. Huo D, Ikpatt F, Khramtsov A, Dangou J-M, Nanda R, Dignam J, et al. Population differences in breast cancer: survey in indigenous African women reveals over-representation of triple-negative breast cancer. J. Clin. Oncol. Off. J. Am. Soc. Clin. Oncol 2009;27:4515-21.

23. Rugo HS, Brufsky AM, Yood MU, Tripathy D, Kaufman PA, Mayer M, et al. Racial disparities in treatment patterns and clinical outcomes in patients with HER2-positive metastatic breast cancer. Breast Cancer Res. Treat 2013;141:461-70. [PubMed: 24062208]

24. Johnson ET. Breast cancer racial differences before age 40--implications for screening. J. Natl. Med. Assoc 2002;94:149-56. [PubMed: 11918384]

25. Krieger N, Chen JT, Waterman PD, Rehkopf DH, Subramanian SV. Painting a truer picture of US socioeconomic and racial/ethnic health inequalities: the Public Health Disparities Geocoding Project. Am. J. Public Health 2005;95:312-323. [PubMed: 15671470]

26. O'Keefe EB, Meltzer JP, Bethea TN. Health Disparities and Cancer: Racial Disparities in Cancer Mortality in the United States, 2000-2010. Front. Public Health 2015;3:51. [PubMed: 25932459]

27. Aizer AA, Wilhite TJ, Chen M-H, Graham PL, Choueiri TK, Hoffman KE, et al. Lack of reduction in racial disparities in cancer-specific mortality over a 20-year period. Cancer 2014;120:1532-9. [PubMed: 24863392]

28. Griffiths RI, Lalla D, Herbert RJ, Doan JF, Brammer MG, Danese MD. Infused Therapy and Survival in Older Patients Diagnosed with Metastatic Breast Cancer who Received Trastuzumab. Cancer Invest 2011;29:573-84. [PubMed: 21929325]

29. Bleicher RJ, Ruth K, Sigurdson ER, Beck JR, Ross E, Wong Y-N, et al. Time to Surgery and Breast Cancer Survival in the United States. JAMA Oncol 2015;1.

30. Social Security Death Master File (SSDMF) [Internet]. Soc. Secur. Adm.

31. Hurvitz S, Guerin A, Brammer M, Guardino E, Zhou Z-Y, Latremouille Viau D, et al. Investigation of Adverse-Event-Related Costs for Patients With Metastatic Breast Cancer in a Real-World Setting. The Oncologist 2014;19:901-8. [PubMed: 25085897]

32. Reid RJ, Roos NP, MacWilliam L, Frohlich N, Black C. Assessing population health care need using a claims-based ACG morbidity measure: a validation analysis in the Province of Manitoba. Health Serv. Res 2002;37:1345-64. [PubMed: 12479500]

33. The Johns Hopkins ACG Case-Mix System Reference Manual Baltimore, MD: The Johns Hopkins University; 2005.

34. Krieger N, Chen JT, Waterman PD, Rehkopf DH, Subramanian SV. Race/ethnicity, gender, and monitoring socioeconomic gradients in health: a comparison of area-based socioeconomic measures--the public health disparities geocoding project. Am. J. Public Health 2003;93:1655-71. [PubMed: 14534218]

35. United States Census Bureau. Geographical Areas Reference Manual Washington, DC: United States Census Bureau; 1994. 
36. US Department of Agriculture. Rural-Urban Commuting Area Codes [Internet]. Econ. Reserach Serv. 01/20166 [cited 2016 Jan 10] Available from: http://www.ers.usda.gov/data-products/ruralurban-commuting-area-codes.aspx

37. Pankratz VS, de Andrade M, Therneau TM. Random-effects Cox proportional hazards model: general variance components methods for time-to-event data. Genet. Epidemiol 2005;28:97-109. [PubMed: 15532036]

38. Dafni U, Grimani I, Xyrafas A, Eleftheraki AG, Fountzilas G. Fifteen-year trends in metastatic breast cancer survival in Greece. Breast Cancer Res. Treat 2010;119:621-31. [PubMed: 19915976]

39. Gennari A, Conte P, Rosso R, Orlandini C, Bruzzi P. Survival of metastatic breast carcinoma patients over a 20-year period: A retrospective analysis based on individual patient data from six consecutive studies. Cancer 2005;104:1742-50. [PubMed: 16149088]

40. Dawood S, Broglio K, Ensor J, Hortobagyi GN, Giordano SH. Survival differences among women with de novo stage IV and relapsed breast cancer. Ann. Oncol. Off. J. Eur. Soc. Med. Oncol. ESMO 2010;21:2169-74.

41. Silber JH, Rosenbaum PR, Clark AS, Giantonio BJ, Ross RN, Teng Y, et al. Characteristics associated with differences in survival among black and white women with breast cancer. JAMA 2013;310:389-97. [PubMed: 23917289]

42. Dawood S, Broglio K, Buzdar AU, Hortobagyi GN, Giordano SH. Prognosis of women with metastatic breast cancer by HER2 status and trastuzumab treatment: an institutional-based review. J. Clin. Oncol. Off. J. Am. Soc. Clin. Oncol 2010;28:92-8.

43. Polite BN, Cirrincione C, Fleming GF, Berry DA, Seidman A, Muss H, et al. Racial Differences in Clinical Outcomes From Metastatic Breast Cancer: A Pooled Analysis of CALGB 9342 and 9840--Cancer and Leukemia Group B. J. Clin. Oncol 2008;26:2659-65. [PubMed: 18509177]

44. Keegan TH, Kurian AW, Gali K, Tao L, Lichtensztajn DY, Hershman DL, et al. Racial/Ethnic and Socioeconomic Differences in Short-Term Breast Cancer Survival Among Women in an Integrated Health System. J. Inf. [Internet] 2015 [cited 2015 Apr 30];105 Available from: http:// ajph.aphapublications.org/doi/10.2105/AJPH.2014.302406

45. Hunt BR, Whitman S, Hurlbert MS. Increasing Black:White disparities in breast cancer mortality in the 50 largest cities in the United States. Cancer Epidemiol 2014;38:118-23. [PubMed: 24602836]

46. Ooi SL, Martinez ME, Li CI. Disparities in breast cancer characteristics and outcomes by race/ ethnicity. Breast Cancer Res. Treat 2011;127:729-38. [PubMed: 21076864]

47. Swede H, Sarwar A, Magge A, Braithwaite D, Cook LS, Gregorio DI, et al. Mortality risk from comorbidities independent of triple-negative breast cancer status: NCI-SEER-based cohort analysis. Cancer Causes Control CCC 2016;

48. Nelson SH, Marinac CR, Patterson RE, Nechuta SJ, Flatt SW, Caan BJ, et al. Impact of very low physical activity, BMI, and comorbidities on mortality among breast cancer survivors. Breast Cancer Res. Treat 2016;155:551-7. [PubMed: 26861056]

49. Dawood S, Broglio K, Gonzalez-Angulo AM, Buzdar AU, Hortobagyi GN, Giordano SH. Trends in Survival Over the Past Two Decades Among White and Black Patients With Newly Diagnosed Stage IV Breast Cancer. J. Clin. Oncol 2008;26:4891-8. [PubMed: 18725649]

50. Polednak AP. Racial differences in mortality from obesity-related chronic diseases in US women diagnosed with breast cancer. Ethn. Dis 2004;14:463-8. [PubMed: 15724763]

51. DeSantis C, Jemal A, Ward E, Thun MJ. Temporal trends in breast cancer mortality by state and race. Cancer Causes Control CCC 2008;19:537-45. [PubMed: 18270799]

52. Henry KA, Sherman R, Farber S, Cockburn M, Goldberg DW, Stroup AM. The joint effects of census tract poverty and geographic access on late-stage breast cancer diagnosis in 10 US States. Health Place 2013;21:110-21. [PubMed: 23454732]

53. Keller D, Guilfoyle C, Sariego J. Geographical influence on racial disparity in breast cancer presentation in the United States. Am. Surg 2011;77:933-6. [PubMed: 21944362]

54. Tatalovich Z, Zhu L, Rolin A, Lewis DR, Harlan LC, Winn DM. Geographic disparities in late stage breast cancer incidence: results from eight states in the United States. Int. J. Health Geogr. [Internet] 2015 [cited 2015 Dec 1];14 Available from: http:/www.ijhealthgeographics.com/ content/14/1/31 


\section{Initial cohort $(\mathrm{N}=66691)$}

Any women aged $25-64$ with at least two independent diagnoses of secondary malignant (SM) neoplasm (ICD-9 codes 196.xx and 199.xx) up to 90 days apart (= disease index

\section{$1^{\text {st }}$ inclusion rule $(\mathrm{N}=\mathbf{2 1 0 7 7})$}

At least 2 independent claims of SM neoplasm up to 90 days apart and at least two independent claims of breast cancer (ICD-9 codes 174-174.9, 233.0) during the 365-days prior to the disease index date
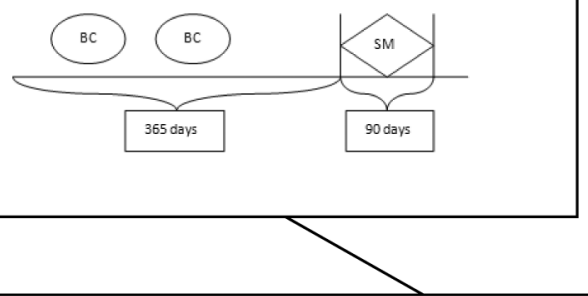

\section{$2^{\text {nd }}$ inclusion rule $(\mathrm{N}=\mathbf{2 6 7 6 0})$}

At least 1 claim during the 365 -days before and 1 claim up to 90 -days after the disease index date

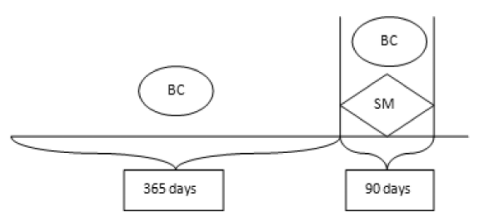

\section{$3^{\text {rd }}$ rule exclusion of other cancers $(N=10253)$}

A diagnosis of cancer other than breast cancer prior to the disease index data (ICD-9 codes 140.xx-165.xx, 170.xx-173, 175.xx, 176.xx, 179.xx-195.xx, and 199.xx-209.xx (excluding skin cancer 173.xx, breast cancer 174.xx and male breast cancer 175.xx and all secondary malignant neoplasm)

Figure 1: Definition of metastatic breast cancer cohort $\mathrm{BC}=$ breast cancer, $\mathrm{N}=$ number, $\mathrm{SM}=$ secondary malignant Source: adjusted from [31] 


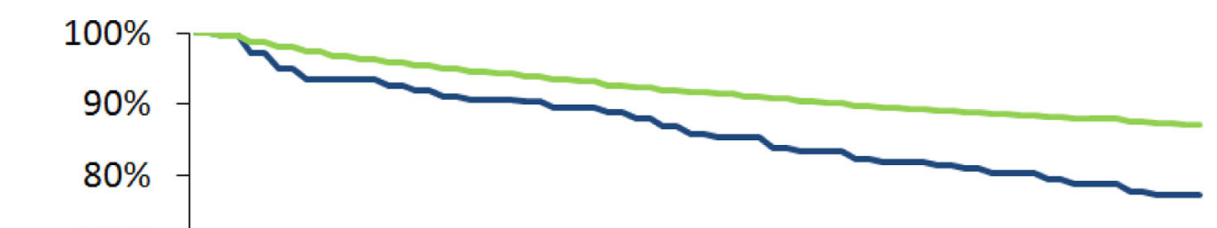

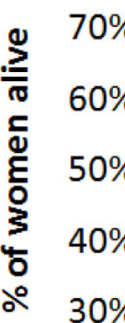

$20 \%$

$10 \%$

$0 \%$

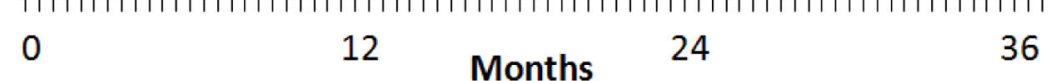

\begin{tabular}{|c|c|c|c|c|}
\hline -African American & 259 & 235 & 216 & 200 \\
\hline Caucasian \& mixed & 6421 & 6057 & 5786 & 5615 \\
\hline
\end{tabular}

Figure 2: 3-year survival stratified by race for women age 25-64 with metastatic breast cancer

African American: residing in predominantly African American ( $\geq 66 \%$ ) neighborhoods

Caucasian: residing in predominantly Caucasian ( $\geq 66 \%$ ) neighborhoods

Mixed: women with Hispanic or Asian surname as well as women residing in predominantly mixed neighborhoods

Plot shows unadjusted mortality during 3-year follow-up.

Total cohort $\mathrm{N}=6680$ as 14 are missing 


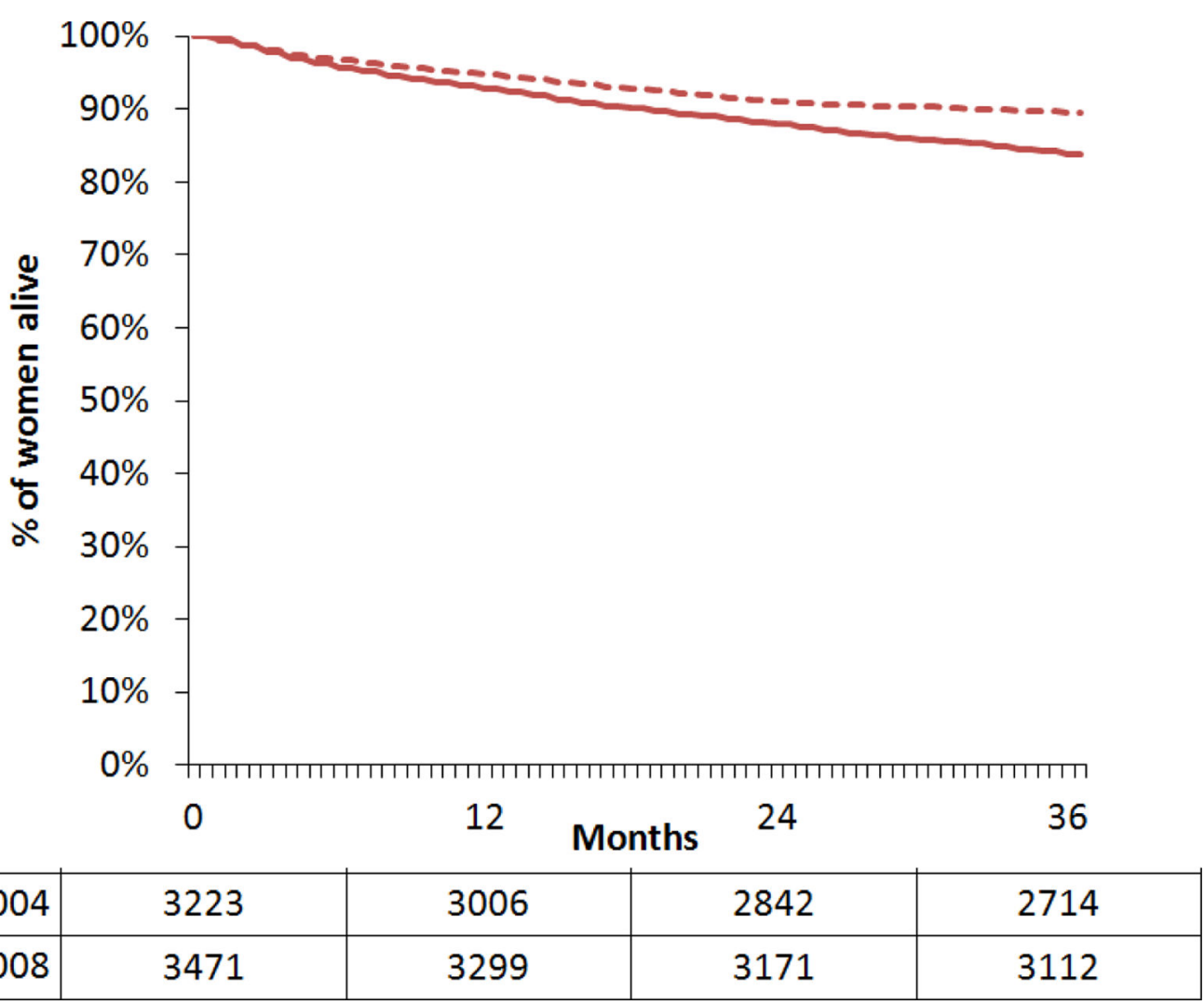

Figure 3: 3-year survival stratified by year of diagnosis for women with metastatic breast cancer Plot shows unadjusted mortality during 3-year follow-up.

Total cohort $\mathrm{N}=6694$ 


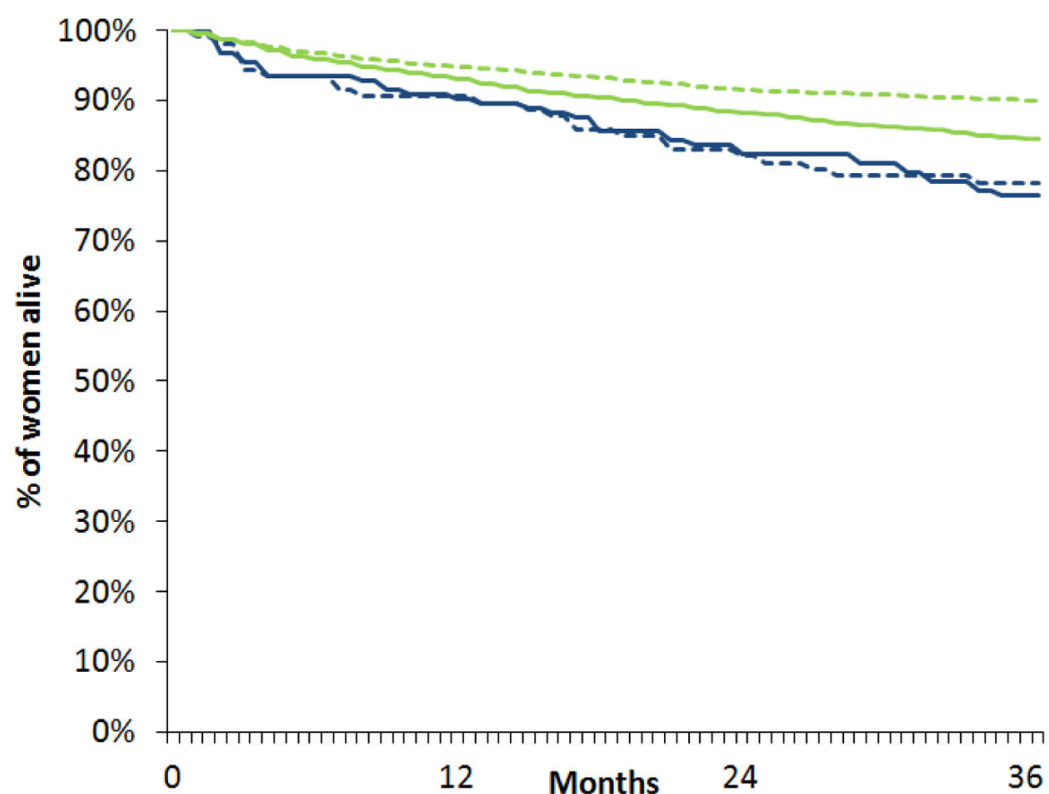

\begin{tabular}{|l|c|c|c|c|}
\hline - African American_2000-2004 & 153 & 139 & 128 & 117 \\
\hline ---- African American_2005-2008 & 106 & 96 & 88 & 83 \\
\hline - Caucasian_2000-2004 & 2555 & 2388 & 2262 & 2167 \\
\hline--- Caucasian_2005-2008 & 2679 & 2548 & 2457 & 2415 \\
\hline
\end{tabular}

Figure 4: 3-year survival stratified by race and year of diagnosis among African American and Caucasian women with metastatic breast cancer

African American: residing in predominantly African American ( $\geq 66 \%$ ) neighborhoods

Caucasian: residing in predominantly Caucasian ( $\geq 66 \%$ ) neighborhoods

Mixed: women with Hispanic or Asian surname as well as women residing in predominantly mixed neighborhoods

Plot shows unadjusted mortality during 3-year follow-up.

Total cohort $\mathrm{N}=5493$ (as mixed $(\mathrm{N}=1187)$ are excluded and 14 are missing) 
Table 1:

Characteristics of US Women with metastatic breast cancer

\begin{tabular}{|c|c|c|c|c|}
\hline \multirow{2}{*}{$\begin{array}{l}\text { Variables } \\
\text { Women }\end{array}$} & \multicolumn{2}{|c|}{$\begin{array}{l}\text { Number }(\%) \\
\text { of women }\end{array}$} & \multicolumn{2}{|c|}{$\begin{array}{l}\text { Unadjusted mortality } \\
\text { during 3-year } \\
\text { follow-up, number (\%) }\end{array}$} \\
\hline & 6694 & $100 \%$ & 884 & $13 \%$ \\
\hline \multicolumn{3}{|c|}{ Neighborhood racial composition ${ }^{1}$ (missing $n=14$ ) } & \multicolumn{2}{|c|}{ (missing $n=3$ ) } \\
\hline African American & 259 & $4 \%$ & 59 & $23 \%$ \\
\hline Mixed & 1187 & $18 \%$ & 157 & $13 \%$ \\
\hline Caucasian & 5234 & $78 \%$ & 665 & $13 \%$ \\
\hline \multicolumn{5}{|l|}{ Age-at-diagnosis } \\
\hline $25-39$ years & 685 & $10 \%$ & 83 & $12 \%$ \\
\hline $40-49$ years & 2241 & $33 \%$ & 279 & $12 \%$ \\
\hline $50-64$ years & 3768 & $56 \%$ & 522 & $14 \%$ \\
\hline \multicolumn{5}{|c|}{ Socio-economic status $(S E S)^{2}$} \\
\hline Low SES & 2051 & $31 \%$ & 302 & $15 \%$ \\
\hline High SES & 4643 & $69 \%$ & 582 & $13 \%$ \\
\hline \multicolumn{5}{|l|}{ Morbidity $(A C G)^{3}$} \\
\hline High morbidity & 1598 & $24 \%$ & 243 & $15 \%$ \\
\hline Low morbidity & 5096 & $76 \%$ & 641 & $13 \%$ \\
\hline \multicolumn{5}{|c|}{ Geographic region (missing $n=5$ ) } \\
\hline Northeast & 716 & $11 \%$ & 68 & $9 \%$ \\
\hline West & 851 & $13 \%$ & 124 & $15 \%$ \\
\hline Midwest & 2353 & $33 \%$ & 308 & $13 \%$ \\
\hline South & 2769 & $41 \%$ & 384 & $14 \%$ \\
\hline \multicolumn{3}{|c|}{ Urban/non-urban area ${ }^{4}$ (missing $n=147$ ) } & \multicolumn{2}{|c|}{ (missing $=27)$} \\
\hline Non-urban & 2037 & $31 \%$ & 279 & $14 \%$ \\
\hline Urban & 4510 & $69 \%$ & 578 & $13 \%$ \\
\hline \multicolumn{5}{|l|}{ Year of diagnosis } \\
\hline $2000-2004$ & 3223 & $48 \%$ & 521 & $16 \%$ \\
\hline $2005-2008$ & 3471 & $52 \%$ & 363 & $10 \%$ \\
\hline
\end{tabular}

${ }^{1}$ African American: residing in predominantly African American ( $\geq 66 \%$ ) neighborhoods

Caucasian: residing in predominantly Causasian ( $266 \%)$ neighborhoods

Mixed = women with Hispanic or Asian surname as well as women residing in predominantly mixed neighborhoods

${ }^{2}$ Low SES: $>25 \%$ only HS education or $>10 \%$ below poverty

High SES: $<25 \%$ only HS education or $<10 \%$ below poverty

3 Very high morbidity: ACG score > 3.0

Low morbidity. ACG score $0-3.0$

4

${ }^{4}$ Non-urban: all remaining categories $2-12$

Urban: large metropolitan area of $1+$ million residents [36] 
ACG $=$ Adjusted Clinical Groups, $\mathrm{HS}=$ high school, $\mathrm{SES}=$ socioeconomic status 
Table 2:

Multivariate analysis of overall survival for women with metastatic breast cancer

\begin{tabular}{|c|c|c|}
\hline \multirow[t]{2}{*}{ Predictors } & \multicolumn{2}{|c|}{ Total mbc cohort $(N=6539)$} \\
\hline & Hazard ratio & $95 \% \mathrm{CI}$ \\
\hline \multicolumn{3}{|c|}{ Ethnicity ${ }^{1}$ (reference $=$ Caucasian) } \\
\hline African American & 1.84 & $1.39-2.45$ \\
\hline Mixed & 1.04 & $0.86-1.26$ \\
\hline \multicolumn{3}{|c|}{ Age-at-diagnose (reference $=50-64$ years $)$} \\
\hline $25-40$ years & 0.85 & $0.67-1.07$ \\
\hline $40-49$ years & 0.89 & $0.77-1.03$ \\
\hline \multicolumn{3}{|c|}{ Socio-economic status ${ }^{2}$ (reference $=$ high $\left.S E S\right)$} \\
\hline Low SES & 1.05 & $0.90-1.23$ \\
\hline \multicolumn{3}{|c|}{ Morbidity ${ }^{3}$ (reference $=10 \mathrm{~W}$ morbidity) } \\
\hline High morbidity & 1.30 & $1.12-1.51$ \\
\hline \multicolumn{3}{|c|}{ Geographic region $($ reference $=$ South $)$} \\
\hline West & 1.20 & $0.97-1.48$ \\
\hline Midwest & 0.95 & $0.81-1.11$ \\
\hline Northeast & 0.73 & $0.56-0.95$ \\
\hline \multicolumn{3}{|c|}{ Urban $/$ non-urban ${ }^{4}($ reference $=$ urban areas $)$} \\
\hline Non-urban areas & 1.09 & $0.94-1.26$ \\
\hline \multicolumn{3}{|c|}{ Year of diagnosis (reference $=2005-2008$ ) } \\
\hline $2000-2004$ & 1.60 & $1.39-1.83$ \\
\hline
\end{tabular}

Bold means significant $\mathrm{p}=<0.05$

${ }^{1}$ African American: residing in predominantly African American ( $\geq 66 \%$ ) neighborhoods

Caucasian: residing in predominantly Causasian ( $266 \%$ ) neighborhoods

Mixed = women with Hispanic or Asian surname as well as women residing in predominantly mixed neighborhoods

${ }^{2}$ Low SES: $>25 \%$ only HS education or $>10 \%$ below poverty

High SES: $<25 \%$ only HS education or $<10 \%$ below poverty

3 Very high morbidity: ACG score > 3.0

Low morbidity: ACG score $0-3.0$

${ }^{4}$ Non-urban: all remaining categories $2-12$

Urban: large metropolitan area of 1+ million residents [36]

ACG = Adjusted Clinical Groups, HS = high school, mbc = metastatic breast cancer, SES = socioeconomic status 